\title{
EVALUATION OF CONCRETE MIXTURES FOR USE IN UNDERWATER REPAIRS
}

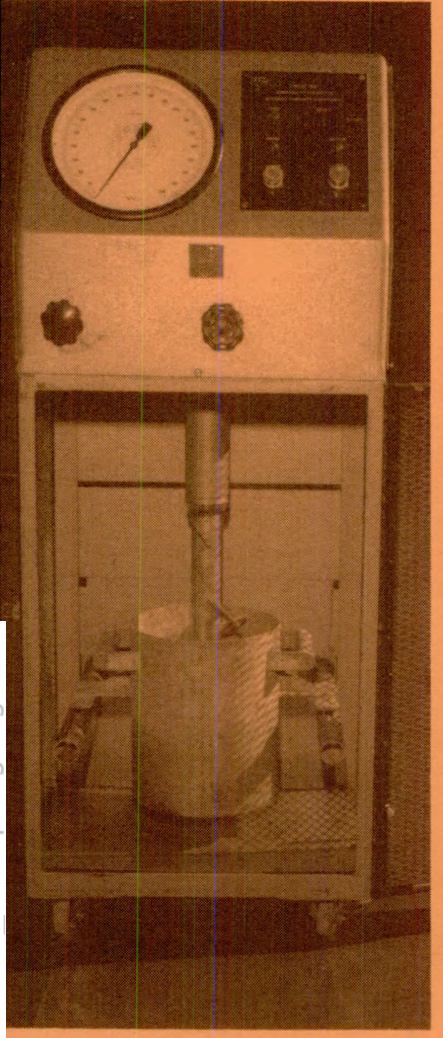

\author{
by \\ Billy D. Neeley \\ Structures Laboratory \\ DEPARTMENT OF THE ARMY \\ Waterways Experiment Station, Corps of Engineers \\ PO Box 631, Vicksburg, Mississippi 39180-0631
}
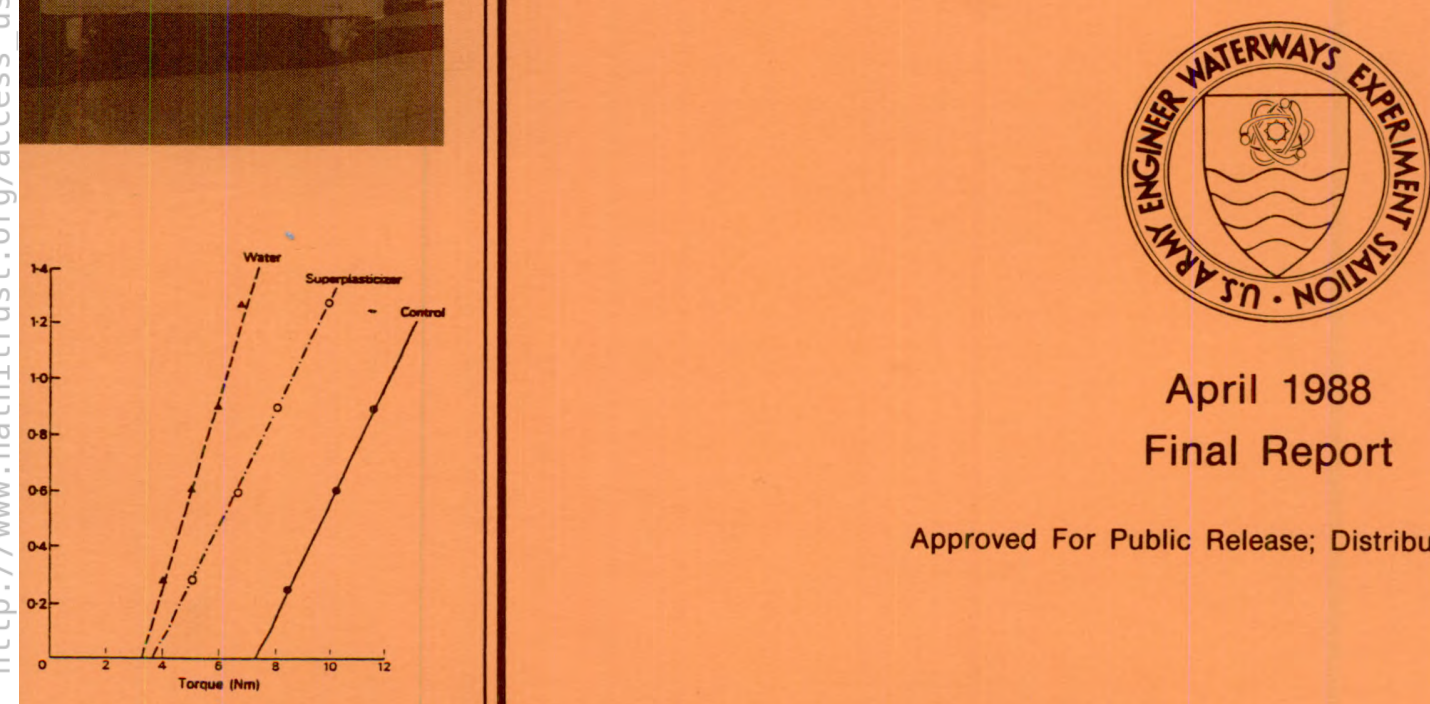

Approved For Public Release; Distribution Unlimited
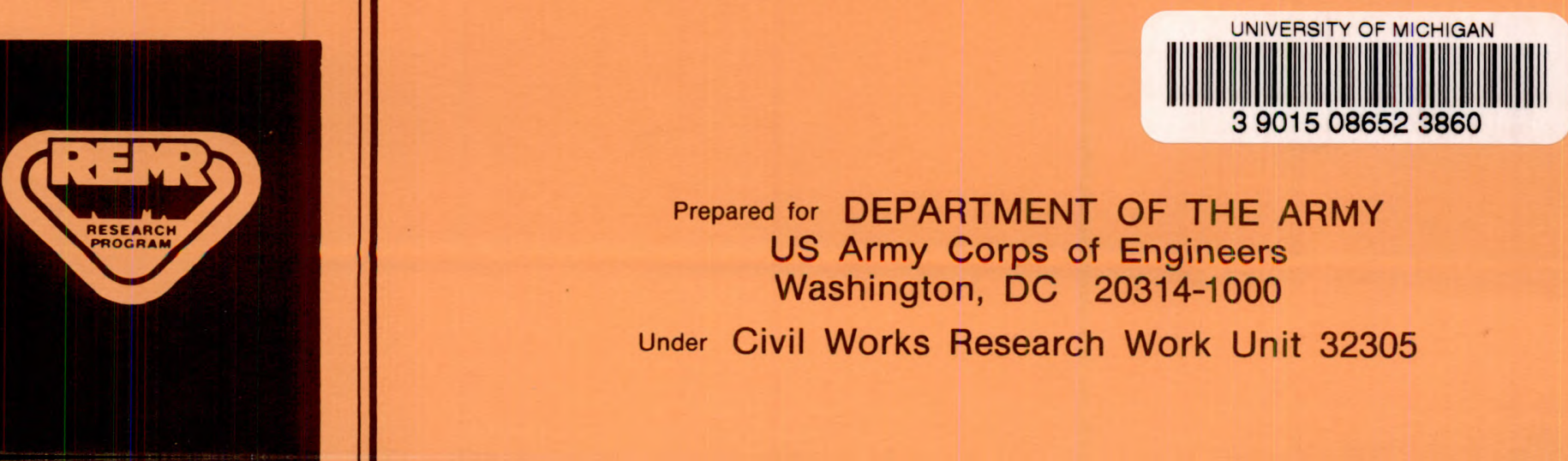

Prepared for DEPARTMENT OF THE ARMY

US Army Corps of Engineers

Washington, DC 20314-1000

Under Civil Works Research Work Unit 32305 